\title{
Sea-ice variability off West Greenland over the last five millennia derived from diatom assemblages
}

\author{
Longbin Sha', H. Jiang', M-S. Seidenkrantz², K.L. Knudsen², J. Olsen³ and A. Kuijpers ${ }^{4}$
}

\begin{abstract}
A diatom-based sea-ice transfer function was developed for the north-western Atlantic. A first reconstruction of seaice concentration off West Greenland shows multi-centennial oscillations superimposed an overall trend of expanding
\end{abstract} sea ice over the last 5000 years.

Sea ice is a sensitive component of the Earth's climate system. It acts as an effective insulator between the oceans and the atmosphere, restricting the exchange of heat, mass, momentum and chemical constituents (Divine and Dick 2006). However, reliable and continuous observations of sea ice only exist since 1978. Extending the sea-ice record further back in time is necessary, e.g. to provide well-constrained boundary conditions and benchmarks for model simulations.

Diatoms are marine siliceous algae which have been used successfully for quantitative reconstructions of sea-ice conditions, mostly in the Southern Ocean (Crosta et al. 1998; Gersonde et al. 2005) but also in the north-western Atlantic (Justwan and Koç Karpuz 2008). We have now established a new diatom-based transfer function for past sea-ice concentrations (SIC) for the region off West Greenland (Fig. 1) and applied it to produce a ca. 5000 year-long reconstruction (Sha et al. 2014)

\section{Modern diatom-SIC dataset}

We determine the modern calibration between diatom assemblages and SIC data based on (1) diatom assemblage analysis from 72 surface sediment samples from the north-western Atlantic (Fig. 1) and (2) monthly means of the satellite SIC data collected from Nimbus-7 SMMR and DMSP SSM/I-SSMIS Passive Microwave Data.

Diatom assemblages are distinguished, with respect to monthly average $\mathrm{SIC}$, using canonical coordination techniques (ter Braak and Šmilauer 2002; Lepš and Šmilauer 2003). Of the 12 monthly mean SICs, only April, August, October, and November SICs influence variations in the diatom data noticeably. And of those months, forward selection and an associated Monte Carlo permutation test reveal that only April and August $\mathrm{SIC}$ s explained a statistically significant $(\mathrm{p}$ $\leq 0.001$ ) amount of variation in the diatom assemblage data, representing $52 \%$ of the total canonical variance. The April SIC alone accounts for $38 \%$ (August 14\%), suggesting that it is the most important environmental control on diatom ecology in this area. This is coherent with the observation that April is one of the most critical months for diatom blooms as the combined light and temperature conditions are often optimal in this month.

\section{Transfer function for April SIC}

Multiple numerical reconstruction methods such as Modern Analogue Technique (MAT, based on one to five analogues), Weight Averaging regression (WA), and Weighted Averaging with Partial Least Squares regression (WA-PLS, based on one to five components) were tested and evaluated for developing the most reliable diatom-based transfer function for April SIC. These tests reveal that the numerical reconstruction based

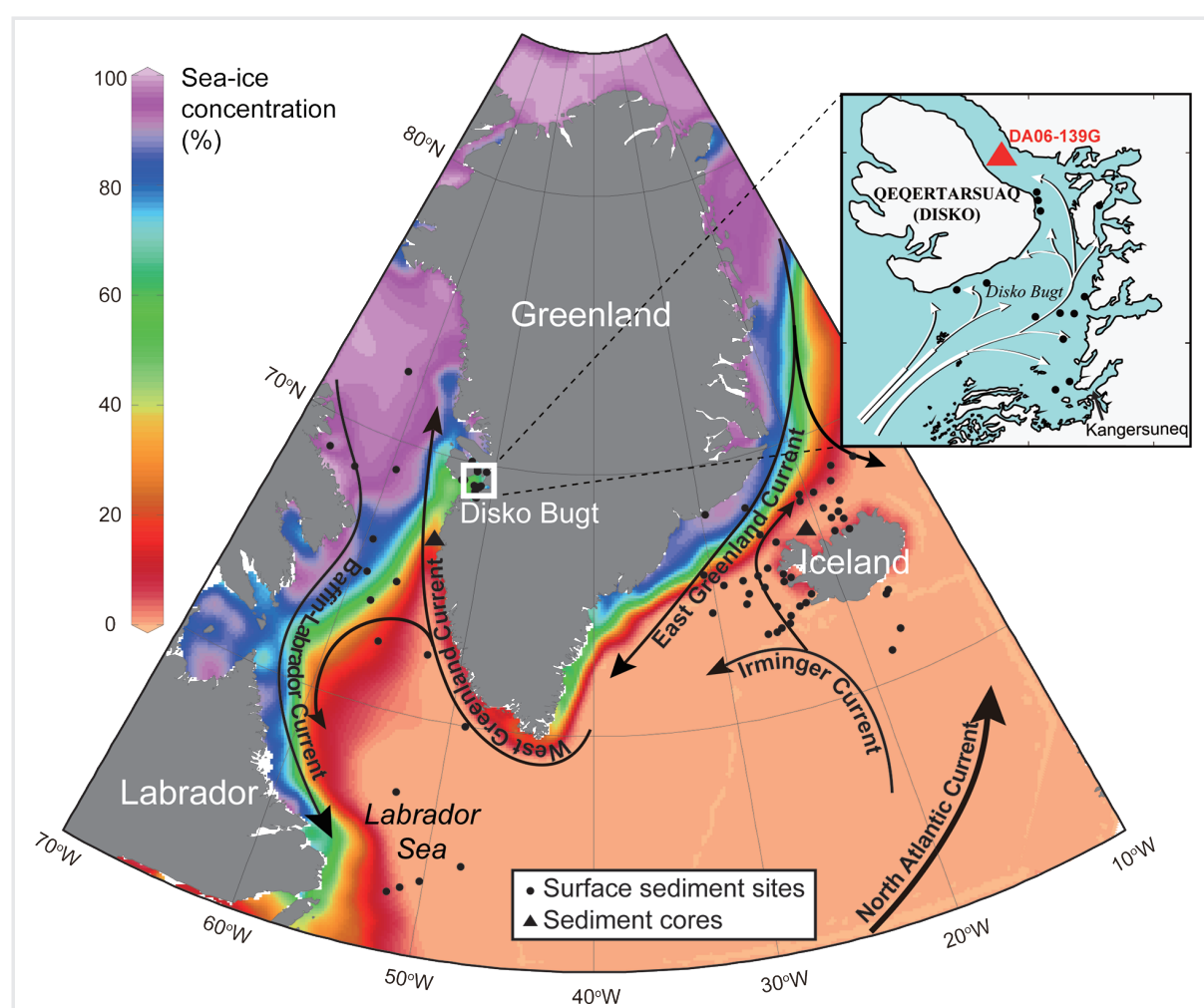

Figure 1: Maps of the NW Atlantic, indicating the prevailing surface currents, the distribution of surface sediment samples for the regional diatom-based sea-ice transfer function, and the locations of the sediment cores mentioned in the text. The satellite April sea-ice concentration for 1979-2010 is indicated as a background.

\section{Testing the SIC reconstruction}

In order to test the reliability of the diatom-based SIC reconstruction as a measure for paleoceanographic changes in the north-western Atlantic region, we compared the reconstructed $\mathrm{SIC}$ of the last $\sim 75$ years from box core GA306-BC4 (445 m water depth) with the satellite SIC record for 19792006 (Fig. 2A). Additionally, we compared our reconstructed $\mathrm{SIC}$ with the model $\mathrm{SIC}$ from the HasISST 1.1 dataset (Rayner et al. 2003) during 1953-2006, and with the mean water temperature in the upper $200 \mathrm{~m}$ west of Fylla Bank during 1963-2006. 


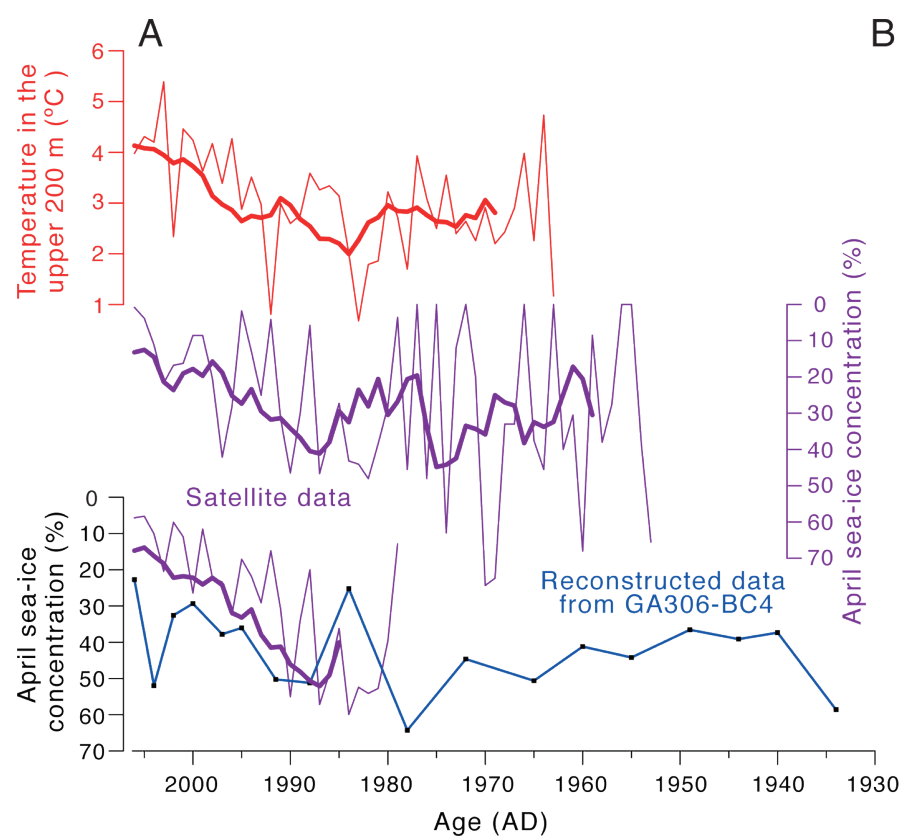

B

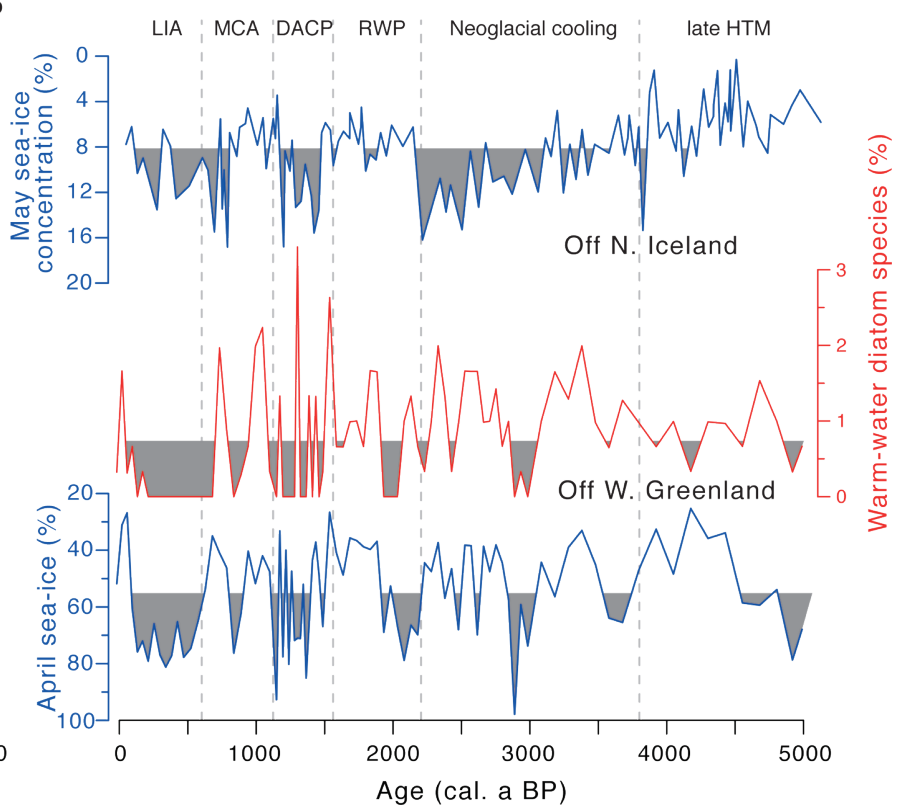

Figure 2: Sea-ice records over the last century and the last 5000 years, respectively. (A) From bottom to top: Reconstructed SIC (blue) from core GA306-BC4 compared with the SIC from satellite observation (red) and model output (purple), and annual mean instrumental temperatures (orange). Original data are shown as thin lines; thick lines are 7-point weighted moving averages. (B) From bottom to top: Reconstructed SIC (blue) and warm-water diatom taxa (green) from core DA06-139G, reconstructed May SIC from core MD99-2269 (purple; Justwan and Koç Karpuz 2008). The gray shading indicates value below each record's mean. Approximate time intervals for historical NE Atlantic climate events are given (LIA: Little Ice Age; MCA: Medieval Climate Anomaly; DACP: Dark Ages Cold Period; RWP: Roman Warm Period; HTM: Holocene Thermal Maximum). Figure modified from Sha et al. (2014).

The diatom-based reconstructed SIC exhibits a generally similar distribution pattern to the satellite and model sea-ice data, as well as the instrumental temperature records, although with a few temporal differences (Fig. 2A). These temporal differences may be caused by uncertainties in the chronology and the low temporal resolution of the sediment core. However, the comparison suggests that overall our diatom-based SIC transfer function is a reliable method for studying paleoceanographic changes in the north-western Atlantic.

\section{A 5000-year record of April SIC}

The transfer function was applied to the diatom assemblages from core DA06-139G (384 m water depth, Fig. 1) to establish an April SIC record for the last 5000 years in the Disko Bugt (Fig. 2B; Sha et al. 2014). The reconstructed SIC values varied between 25 $95 \%$ around a mean of $55 \%$, with an overall trend towards increasing sea ice. Between 5000 and $3860 \mathrm{cal} \mathrm{yr} \mathrm{BP,} \mathrm{our} \mathrm{results} \mathrm{suggest}$ that the SIC was generally below the mean value except for a short period around 4900 cal yr BP. This coincides with relatively warm conditions suggested by an abundance of warm-water diatom species (Fig. 2B). This period corresponds to the latest part of the Holocene Thermal Maximum. Between 3860 and $1510 \mathrm{cal}$ yr BP SIC oscillated around the mean value. From 1510-1120 cal yr BP and after $650 \mathrm{cal}$ yr BP was above the mean, indicating that sea-ice cover in Disko Bugt was particularly extensive.

Warm-water diatom species reflect warm Atlantic water, as evidenced by the abundant distributions in surface sediments (Sha et al. 2014). The distribution pattern of sea-ice diatom species correlates well with the strength of cold polar water from the East Greenland Current (Sha et al. 2014). Agreement between reconstructed $\mathrm{SIC}$ and changes in the diatom species suggests that sea-ice conditions in Disko Bugt were influenced by variations in the relative strength of the two main components of the West Greenland Current, i.e. the cold East Greenland Current carrying polar water from the Arctic Ocean and the relatively warm Irminger Current of Atlantic origin (Fig. 2B). The North Icelandic shelf was influenced by both the Irminger Current and the East Greenland Current. A diatom-inferred May SIC record from there, shows a similar SIC pattern to that found in the Disko Bugt, particularly during the time periods before $3500 \mathrm{cal} \mathrm{yr} \mathrm{BP}$ and after 2000 cal yr BP (Justwan and Koç Karpuz 2008; Fig. 2B). Differences observed between the two reconstructions during the $3500-2000 \mathrm{cal} \mathrm{yr}$ BP time interval may reflect that the different approaches used to reconstruct past sea-ice variations could describe different aspects of sea-ice cover. Finally, a preliminary comparison between the reconstructed SIC record and total solar irradiance suggests a relationship between solar forcing and seaice changes (Sha et al. 2014).

\section{Outlook}

We established a new diatom-based SIC transfer function for the north-western Atlantic region and provided a quantitative reconstruction of April sea-ice conditions in this region over the last 5000 years.

Discussions remain about what causes seaice variations in the area and more detailed analysis are currently being performed to decipher the controlling factors.

In spite of its advantage for quantitatively extending sea-ice record to geological past, our diatom-based SIC transfer function still has some limitation due to re-suspension and preservation of some diatom species through time. In order to reconstruct sea-ice variability with confidence, a multi-method strategy will be focused on, which may capture complementary information from the complex relationships between surface sediment diatoms and the modern environmental variables.

\section{AFFILIATIONS}

'Key Laboratory of Geographic Information Science, East China Normal University, Shanghai, China

${ }^{2}$ Centre for Past Climate Studies and Arctic Research Centre, Aarhus University, Denmark

${ }^{3}$ Department of Physics and Astronomy, Aarhus University, Denmark

${ }^{4}$ Geological Survey of Denmark and Greenland (GEUS), Copenhagen, Denmark

\section{CONTACT}

Longbin Sha: shalongbin@hotmail.com

\section{REFERENCES}

Crosta X et al. (1998) Paleoceanography 13: 284-297

Divine DV, Dick C (2006) J Geophys Res 111 doi:10.1029/2004JC002851

Gersonde R et al. (2005) Quat Sci Rev 24: 869-896

Justwan A, Koç Karpuz N (2008) Mar Micropaleontol 66: 264-278

Lepš J, Šmilauer P (2003) Multivariate analysis of ecological data using CANOCO, Cambridge University Press, $283 \mathrm{pp}$

Rayner NA et al. (2003) J Geophys Res Atmos 108, doi:10.1029/2002JD002670

Sha L et al. (2014) Palaeogeog Palaeoclimatol Palaeoecol 403: 66-79

ter Braak CJF, Šmilauer P (2002) CANOCO reference manual and CanoDraw for windows user's guide: software for canonical community ordination (version 4.5), Microcomputer Power, 500pp 